\title{
Genomewide association for schizophrenia in the CATIE study: results of stage 1
}

PF Sullivan, D Lin, J-Y Tzeng, E van den Oord, D Perkins, TS Stroup, M Wagner, S Lee, FA Wright, F Zou, W Liu, AM Downing, J Lieberman and SL Close

Molecular Psychiatry (2009) 14, 1144; doi:10.1038/mp.2008.74

Correction to: Molecular Psychiatry (2008) 13, 570-584;

For technical reasons, Supplementary Tables 2, 3 and doi: $10.1038 / \mathrm{mp} .2008 .25$

4 were not published online. They now appear online at www.nature.com/mp.

Supplementary Information accompanies the paper on the Molecular Psychiatry website (http://www.nature.com/mp)

\section{Clearance mechanisms of Alzheimer's amyloid- $\beta$ peptide: implications for therapeutic design and diagnostic tests}

\author{
KA Bates, G Verdile, Q-X Li, D Ames, P Hudson, CL Masters and RN Martins
}

Molecular Psychiatry (2009) 14, 1144; doi:10.1038/mp.2008.123

Correction to: Molecular Psychiatry (2009) 14, 469-486;

doi: $10.1038 / \mathrm{mp} .2008 .96$

Following the publication of the above article, the authors noted errors in Table 1 . The revised table appears below:

Table 1 Soluble (aqueous buffer soluble) and insoluble (aqueous buffer insoluble) A $\beta$ levels in human AD and control brains from a selection of publications

\begin{tabular}{|c|c|c|c|c|c|c|c|}
\hline \multirow{2}{*}{$\begin{array}{l}\text { Study } \\
\text { (reference) }\end{array}$} & \multirow{2}{*}{$\begin{array}{l}\text { Area } \\
\text { measured }\end{array}$} & \multirow[t]{2}{*}{ Sample } & \multicolumn{2}{|c|}{$A \beta(\mu g / g$ wet tissue $)$} & \multirow[t]{2}{*}{ Total $A \beta$} & \multirow[t]{2}{*}{$\%$ Soluble } & \multirow[t]{2}{*}{ Methods } \\
\hline & & & Soluble & Insoluble & & & \\
\hline \multirow[t]{2}{*}{ Fonte et $a l^{24 a}$} & \multirow[t]{2}{*}{ Frontal cortex } & Control (14) & (Not determined) & & $0.1 \pm 0.1$ & & WB (WO2) \\
\hline & & $\mathrm{AD}(17)$ & 1.11 & 9.99 & $11.1 \pm 3.1$ & 10 & \multirow{3}{*}{ WB (WO2) } \\
\hline \multirow[t]{2}{*}{ McLean et al. ${ }^{26}$} & \multirow[t]{2}{*}{ Superior frontal gyrus } & Control (18) & $<0.1 \pm 0.1$ & $1.9 \pm 2.5$ & 2.0 & $<4.7$ & \\
\hline & & $\mathrm{AD}(18)$ & $0.3 \pm 0.3$ & $20.6 \pm 11.1$ & 20.1 & 1.4 & \\
\hline \multirow[t]{3}{*}{ Lue et $a .^{25 \mathrm{~b}}$} & \multirow[t]{3}{*}{ Superior frontal gyrus } & Control (8) & $0.003 \pm 0.002$ & $13.0 \pm 5.9$ & $13.0 \pm 5.9$ & 0.02 & \multirow[t]{3}{*}{$\begin{array}{l}\text { ELISA (R163/ } \\
\text { R165-4G8) }\end{array}$} \\
\hline & & $\begin{array}{l}\text { Neurological } \\
\text { control (8) }\end{array}$ & $0.018 \pm 0.008$ & $116.4 \pm 13.2$ & $116.4 \pm 13.2$ & 0.02 & \\
\hline & & $\mathrm{AD}(8)$ & $0.107 \pm 0.024$ & $247.0 \pm 56.0$ & $247.1 \pm 56.0$ & 0.04 & \\
\hline \multirow[t]{2}{*}{$\begin{array}{l}\text { Fodero-Tavoletti } \\
\text { et al. }{ }^{27}\end{array}$} & \multirow[t]{2}{*}{ Cerebral cortex } & Control (3) & $0.02 \pm 0.0006$ & $0.02 \pm 0.003$ & $0.04 \pm 0.0$ & 50 & \multirow[t]{2}{*}{$\begin{array}{l}\text { ELISA } \\
\text { (G210/G211-WO2) }\end{array}$} \\
\hline & & $\mathrm{AD}(3)$ & $0.55 \pm 0.17$ & $4.9 \pm 1.5$ & 5.4 & 10.2 & \\
\hline \multirow[t]{3}{*}{ Wang et $a l^{28 \mathrm{c}}$} & \multirow[t]{3}{*}{$\begin{array}{l}\text { Cerebral } \\
\text { cortex }\end{array}$} & Control (10) & 0.009 & 0.009 & 0.02 & 45 & \multirow[t]{3}{*}{$\begin{array}{l}\text { ELISA (BAN50-BA27/ } \\
\text { BC05) }\end{array}$} \\
\hline & & $\begin{array}{l}\text { Neurological } \\
\text { control (10) }\end{array}$ & 0.14 & 5.0 & 2.7 & 5.1 & \\
\hline & & $\mathrm{AD}(23)$ & 2.8 & 9.5 & 12.3 & 22.7 & \\
\hline \multirow[t]{2}{*}{ Hellstrom-Lindahl et $a{ }^{29 b}$} & Frontal cortex & Controls (10) & $0.00 \pm 0$ & $0.0007 \pm 0.0001$ & $0.0007 \pm 0.0001$ & 0 & $\begin{array}{l}\text { ELISA (Signal select } \\
\text { Biosource) }\end{array}$ \\
\hline & Temporal cortex & $\begin{array}{l}\mathrm{AD}(7) \\
\text { Controls (7) } \\
\mathrm{AD}(7)\end{array}$ & $\begin{array}{c}0.0002 \pm 0.00 \\
0 \\
0.049-0.107\end{array}$ & $\begin{array}{c}0.0035 \pm 0.0007 \\
<0.0019 \\
0.492-0.813\end{array}$ & $\begin{array}{c}0.0037 \\
<0.0059 \\
0.599 \pm 0.257\end{array}$ & $\begin{array}{l}5.4 \\
0 \\
8.2\end{array}$ & ELISA (Biosource, 4G8) \\
\hline
\end{tabular}

Abbreviations: A $\beta$, amyloid- $\beta$; AD, Alzheimer's disease; ELISA, enzyme-linked immunosorbent assay; WB, western blot.

The sample size from each paper is given in parentheses in the sample column, and the antibody used is given in parentheses in the methods column,

values presented as mean \pm s.e.m. (except for where noted).

${ }^{\mathrm{a}}$ Values reported as $\mu \mathrm{g} / \mathrm{g}$ total protein rather than $\mu \mathrm{g} / \mathrm{g}$ wet tissue.

${ }^{\mathrm{b}}$ Combined $\mathrm{A} \beta 40$ and $\mathrm{A} \beta 42$ values for the soluble and insoluble pool.

${ }^{\mathrm{C}}$ Soluble designated as $\mathrm{A} \beta 40$, insoluble as $\mathrm{A} \beta 42$.

${ }^{\mathrm{d}}$ Values converted to $\mu \mathrm{g} / \mathrm{g}$ total protein using the molecular weight of $\mathrm{A} \beta 40$ and presented as the range. 